\title{
Метаморфизм Центрально-Бунделкхандского зеленокаменного комплекса Бунделкхандского кратона Индийского щита
}

\author{
Сибелев О.С. ${ }^{1}$, Слабунов А.И. ${ }^{1}$, Мишра С. ${ }^{2}$, Сингх В. ${ }^{3}$ \\ ${ }^{1}$ Институт геологии КарНЦ РАН, Петрозаводск, Россия, Sibelev@krc.karelia.ru \\ ${ }^{2}$ Геологический факультет Университета Хемвати Нандан Бахугуна Гарваль, Индия, smpsgeо@gтаil.com \\ ${ }^{3}$ Геологический факультет Бунделкхандского университета, Джанси, Индия, vinodksingh@bujhansi.ac.in
}

Аннотация. В метавулканитах Маурнипурской структуры Центрально-Бунделкхандского зеленокаменного комплекса установлены три стадии метаморфизма: 1) амфиболитовой фации с возрастом около $2687 \pm 17$ Ма, 2) его регрессивная ветвь и сопряженные гидротермальные процессы пропилитизации, 3) пренит-пумпеллиитовой фации, вероятно связанный с формированием гидротермальных кварцевых жил $(1866 \pm 11$ и $1779 \pm 43$ млн. лет). В работе приведены данные о минеральных ассоциациях, составе минералов и РТ-параметрах метаморфических преобразований.

Ключевые слова: архей, зеленокаменный комплекс, метаморфизм, метасоматоз, минеральные ассоциации, гранат, РТ-параметры, Бунделкхандский кратон, Индийский щит.

\section{Metamorphism of the Central Bundelkhand greenstone complex of the Bundelkhand craton, Indian Shield}

\author{
Sibelev O.S. ${ }^{1}$, Slabunov A.I. ${ }^{1}$, Mishra S. ${ }^{2}$, Singh V.K. ${ }^{3}$ \\ ${ }^{1}$ Karelian Research Centre, RAS, Institute of Geology, Petrozavodsk, Rassia, Sibelev@krc.karelia.ru \\ ${ }^{2}$ Department of Geology, Hemvati Nandan Bahuguna Garhwal University, India, smpsgeo@gmail.com \\ ${ }^{3}$ Department of Geology, Institute of Earth Sciences, Bundelkhand University, Jhansi, India, \\ vinodksingh@bujhansi.ac.in
}

\begin{abstract}
Three stages of metamorphism have been registered in metavolcanic rocks of Central Bundelkhand greenstone complex in Murinipura belt, as follows: 1) the amphibolite facies with an age of about $2687 \pm 17 \mathrm{Ma}, 2)$ its regressive phase and related hydrothermal processes of propylitic alteration, 3) prehnite-pumpellyite facies, probably attributed to formation of hydrothermal quartz veins (ca. $1866 \pm 11$ and $1779 \pm 43 \mathrm{Ma}$ ). The paper presents data on mineral associations, mineral composition and PT-parameters of metamorphic transformations.
\end{abstract}

Key words: metamorphism, metasomatism, greenstone complex, mineral associations, garnet, PT conditions, Bundelkhand craton, Indian Shield.

\section{Введение}

Метаморфическая история геологических комплексов является критично важной для понимания их геодинамической природы (Метаморфизм..., 2001). Однако метаморфизм пород Бунделкхандского кратона изучен очень слабо и данная работа - это попытка начать решать эту проблему.

\section{Геологический очерк}

Бунделкхандский кратон состоит, главным образом, из неоархейских микроклиновых гранитов (Ramakrishnan, Vaidyanadhan, 2010; Singh et al., 2019). Среди них встречаются крупные фрагменты разгнейсованных гранитоидов ТТГ серии. Их возраст оценивается в 3.59-3.2 млрд. лет (Kaur et al., 2014). Важную роль в структуре кратона играют зеленокаменные пояса, сложенные мезонеоархейским Центрально-Бунделкхандским (ЦБЗК) и Южно-Бунделкхандским зеленокаменными комплексами (Singh, Slabunov, 2015, 2016; Slabunov, Singh, 2018). ЦБЗК, который рассматривается в данной работе, слагает Бабинский и Мауранипурский пояса, простирающиеся с запада на восток приметно на 150 км (рис. 1).

Супракрустальные образования ЦБЗК состоят из двух стратотектонических ассоциаций: ранней, представленной тремя толщами 1) ультрабазит-метабазальтовой, 2) метариолит-дацитовой и 3) железистыми кварцитами (BIF) и поздней, сложенной кислыми вулканитами. Контакты между толщами и ассоциациями тектонические (Singh, Slabunov, 2015; Slabunov, Singh, 2018). Места- 


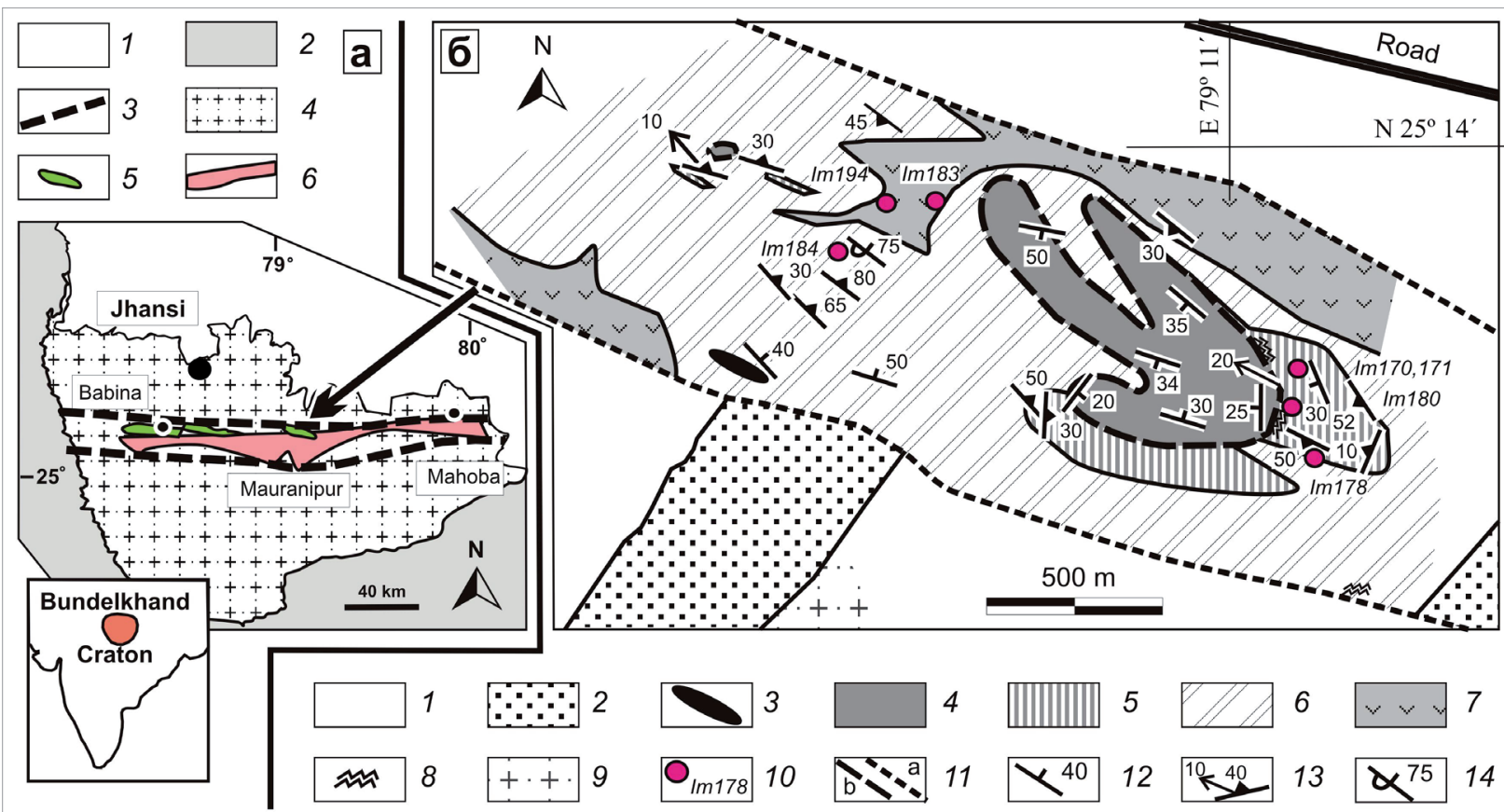

Рис. 1. а - Схема расположения Центрально-Бунделкхандского террейна (Slabunov, Singh, 2019): 1 - аллювиальные отложения, 2 - мезо-палепротерозойские осадочные комплексы, 3 - границы террейнов, 4 - неоархейские Бунделкхандские гранитоиды, 5 - мезо-неоархейские зеленокаменные комплексы, 6 - архейские ТТГ комплексы; б - схема геологического строения Мауранипурского зеленокаменного пояса Бунделкхандского кратона (по Slabunov, Singh, 2018, с упрощениями): 1 - аллювиальные отложения; 2 - кварцевые жилы (рифы) (1.9-1.8 млрд. лет); 3-7 - зеленокаменный комплекс: 3 - дайка кислых пород (2.56 млрд. лет), 4 - полосчатые кварциты (BIF), 5 - кислые метавулканиты (2.81 млрд. лет), 6 - метабазальты (местами с реликтами шаровой текстуры), 7 - метаультрамафиты и высокомагнезиальные основные породы; 8 - метасоматические породы (около 2.7 млрд. лет), 9 -гранитоиды (3.55-2.5 млрд. лет), 10 - точки отбора образцов и их номер, 11 - предполагаемые разломы (а) и надвиги (б), 12-14 - элементы залегания: 12 - полосчатости, 13 - сланцеватости и линейности, 14 - опрокинутое залегание.

Fig. 1. a - Location of the Central-Bundelkhand Terrain (Slabunov, Singh, 2019): 1 - alluvial deposits, 2 - MesoPaleoproterozoic deposits, 3 - Boundary of the Central-Bundelkhand terrain, 4 - Neoarchean Bundelkhand granitoids, 5 - Meso-Neoarchean greenstone complexes, 6 - Archean TTG complexes; b - Scheme of the geological structure of the Mauranipur greenstone belt, Bundelkhand craton (after A.I. Slabunov and V.K. Singh, 2018, with simplifications): 1 - alluvial deposits, 2 - quartz veins (reefs) (1.9-1.8 Ga); 3-7 - greenstone complex: 3 - felsic dike (2.56 Ga), 4 - banded iron formation (BIF), 5 - felsic metavolcanic rocks $(2.81 \mathrm{Ga}), 6$ - metabasalts (in some cases with relics of pillow structure), 7 - meta-ultramafics and high-Mg basalts; 8 - metasomatic rocks (about $2.7 \mathrm{Ga}$ ), 9 - granitoids (3.55-2.5 Ga), 10 - sampling points with number, 11 - alleged faults (a) and thrusts (b), 12 - bedding, 13 - foliation and linearity, 14 - overturned bedding.

ми в зонах этих контактов формируются эпидот-кварц-плагиоклазовые метасоматиты. Возраст ран-

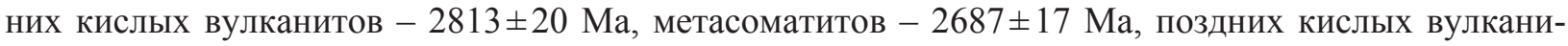
тов - 2542-2557 (Singh, Slabunov, 2015; Slabunov, Singh, 2018). Возраст метасоматитов интерпретируется как время метаморфизма, синхронного с ранней аккреционной стадией становления пояса. Однако в ранней стратотектонической ассоциации ЦБЗК установлены и более древние проявления метаморфизма: около 2.78 (до эклогитовой фации), $2.73 \mathrm{Ga}$ (Saha et al., 2011). Архейские гранитзеленокаменные комплексы секутся тремя разновозрастными (около 1.98, 1.8 и 1.0 млрд. лет) генерациями даек габброидов (Ramakrishnan, Vaidyanadhan, 2010; Pradhan et al., 2012). Кроме того, широко проявлены палеопротерозойские гидротермальные процессы, в ходе которых сформировался уникальный рой гигантских (отдельные жила прослежиаются по простиранию на примерно 100 км при мощности до 700 м) кварцевых жил (Ramakrishnan, Vaidyanadhan, 2010; Pati et al,, 2007). Воз- 
раст ранней стадии их формирования оценивается в 1866 \pm 11 млн лет, а позденй $-1779 \pm 43$ (Slabunov et al., 2017).

\section{Минеральные ассоциации и состав минералов}

В целях оценки параметров метаморфизма изучались минеральные ассоциации метавулканитов, метаультрамафитов и метабазальтов р-нов Мауранипур и Бабина. Эти ассоциации многофазны, зачастую метастабильны и представлены реликтовыми, метаморфическими и метасоматическими минералами. Почти все они сохраняются до последних стадий бластеза. К относительно высокотемпературным парагенезисам, содержащим Cpx, Grt, Am и Pl, с падением температуры добавляются регрессивные минералы (Ms, Ksp, Act, Ep, Chl, Cc и дp), а их кристаллизация все отчетливей приобретает метасоматический характер. На заключительных стадиях формируются парагенезисы с пренитом и пумпеллиитом.

Гранаты в этих породах уникальны и характеризуются высокими содержаниями Sps минала (до 44\%), низкими - Pyr и колоссальными вариациями содержаний Alm и Grs как в общей выборке, так и в пределах отдельно взятых зерен (рис. 2a). Состав Grt закономерно изменяется не столько в рамках отдельных серий, сколько «поперек» этих серий - от пиральспитовых разновидностей к уграндитовым. Включения представлены Qz, Am, Chl, Grs, Ilm и Pmp. Многочисленные трещинки выполнены Chl, Kfs, Prh и Grs (стрингеры). Химическая зональность контрастна. Центральные участки зерен обогащены $\mathrm{Fe}$ и обеднены Сa. К краевым участкам зерна резко возрастает концентрация Са при падении содержаний Fe. Вариации содержаний $\mathrm{Mg}$ и $\mathrm{Mn}$ не так значительны. Формирование стрингеров протекало на относительно ранних стадиях бластеза.

Амфиболы характеризуются аномально широким спектром составов (рис. 2б): от Prg-Ts и $\mathrm{Mg}-\mathrm{Hbl}$, до Act и Cum-Gru. При значительных колебаниях $\mathrm{X}_{\mathrm{Mg}}$ для выборки в целом, ее изменения каждого отдельно взятого образца невелики и за счет большого разброса содержаний Si их фигуративные точки имеют вид пологих трендов (на рис. совмещены поля кальциевых амфиболов с показателями щелочности больше и меньше 0.5 форм. ед., граница фигуративных точек этих групп амфиболов показана ломаной линией). Наиболее низкокремнистые амфиболы обогащены щелочами. Можно предположить, что вариации $\mathrm{X}_{\mathrm{Mg}}$ амфиболов связаны с составом протолита, а значительные изменения их глиноземистости - следствие интенсивной регрессивно-метаморфической (и метасоматической) проработки.

Клинопироксен - типоморфный минерал мафитов-ультрамафитов интенсивно замещается $\mathrm{Am}$ и порой полностью исчезает. Мелкие зерна Срх фиксируются и в кислых вулканитах, что указывает на его вторичный генезис. Проанализированные Срх относятся к группе диопсидов. Na и какие-либо изоморфные примеси в них практически отсутствуют. Единственный химический анализ в поле $\mathrm{Fe}-\mathrm{Mg}$ Рх по оптическим данным принадлежит энстатиту. Хлорит ассоциируя с Ер и
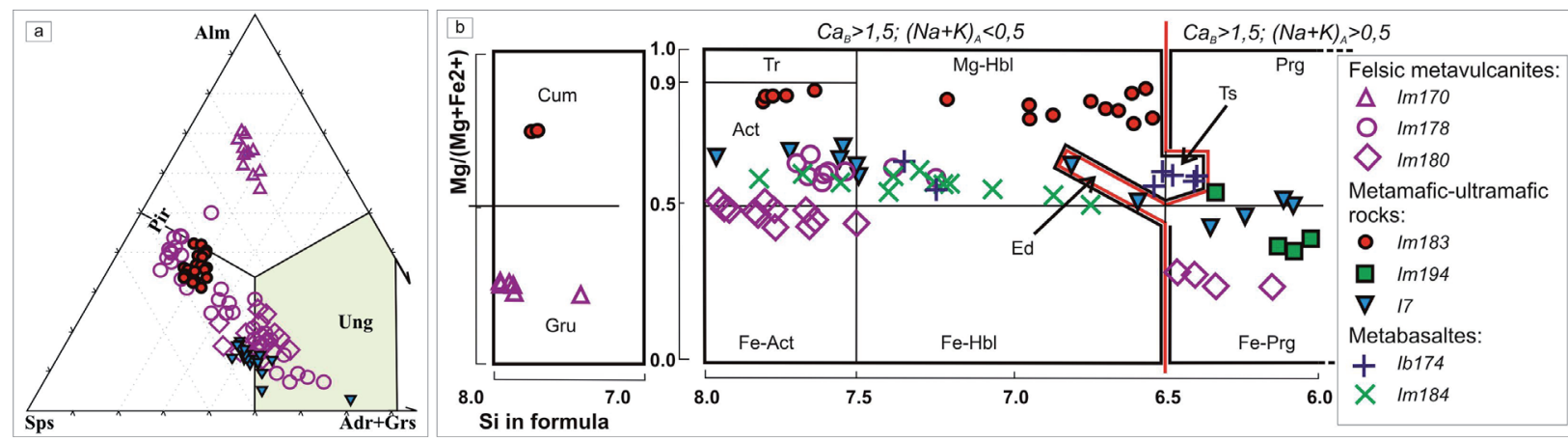

Рис. 2. а - Компонентный состав проанализированных гранатов в координатах Sps - Alm - (Adr+Grs), c выделенными полями пиральспитовой (Pir) и унграндитовой (Ung) серий (Grew et al. 2013); б - составы амфиболов на классификационных диаграммах (Nomenclature..., 1997).

Fig. 2. a - The composition of the analyzed garnets in the coordinates of Sps - Alm - (Adr+Grs), with selected fields of pyralspit (Pir) and unngrandit (Ung) series (Grew et al., 2013); b - the compositions of amphiboles on the classification diagrams (Nomenclature ..., 1997). 
Prh отвечает преимущественно пикнохлоритам и клинохлорам, характерным для пропилитов. Биотит не зафиксирован, но часто встречаются зерна слюдистого габитуса, представляющие собой не диагностируемую микрозондовым методом смесь минералов (Bt c Chl или с Ms?). Немногочисленные проанализированные мусковиты по составу близки к фенгитовой подгруппе. Эпидоты (Czo-Zo) широко распространены в рассматриваемых породах, участвуя в гидротермальных процессах и ассоциируя c Qz, Hbl, Act, Kfs и Alb. Пренит развивается преимущественно в виде секущих жилок, (М до 1 см) или мелких зерен в матриксе, замещающих Pl. Характерная черта пренита - постоянство химического состава и отсутствие примесей. Он парагенетичен с кальциевым Grt и пумпеллиитом$(\mathrm{Mg})$. Акцессорные и рудные минералы разнообразны и порой занимают довольно значительные объемы. Так, в некоторых образцах объемные количества Ttn, Mag или Mn-Ilm могут достигать 3 и более \%.

\section{РТ-параметры метаморфизма}

Парагенетический анализ и химический состава минералов позволяют качественно оценить условия метаморфических преобразований. Присутствие минеральных ассоциаций Срх с высокоглиноземистыми Am дает основание для оценки пика метаморфизма на уровне амфиболитовой фации. Классические методы термобарометрии дают параметры 586-679 ${ }^{\circ} \mathrm{C}$ при 6.7-7.2 кбар (Powell R., 1985, Blundy J.D., Holland T.J.B. 1990, Schmidt M.W. и др.) и широкий спектр PT значений ниже этого уровня, часть из которых находится в области устойчивости силлиманита. Корректные TWQдиаграммы (Berman, 1991, БД 1992, TWQ_Comb TWQ_View Д.В. Доливо-Добровольский) пока удалось получить лишь для регрессивных стадий на умеренноградиентном тренде (рис. 3).

Температурные рамки пропилитизации $-200-350^{\circ} \mathrm{C}$, при почти гипабиссальных условиях (Метасоматизм..., 1998; Русинов, 1972). В этих же границах Т располагается и поле Prh-Pmp фации, но учитывая барофильность Pmp и парагенетичность Ca-Grt, можно предположить здесь относительно более высокие давления.
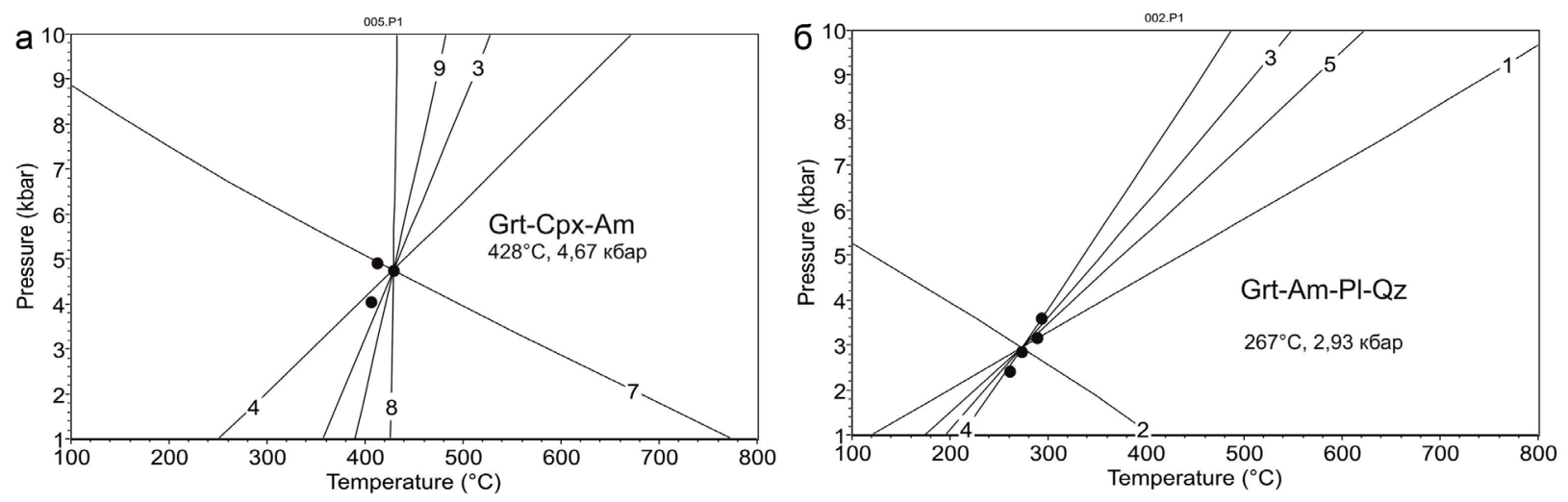

Рис. 3. TWQ диаграммы: а - метаультрамафита и б - метабазальта.

Fig. 3. TWQ diagrams: $a-$ metaultramafic and $b-$ metabasalt.

\section{Заключение}

Наиболее ранними проявлениями метаморфизма в Центрально-Бунделкхандском террейне, по-видимому, являются процессы преобразования мафитов в условиях эклогитовой фации, возраст которого оценивается в $2780 \pm 64$ млн. лет (Saha et al., 2011). Описанные в работе метаморфические процессы в метавулканитах Центрально-Бунделкхандского зеленокаменного комплекса достигали довольно высоких параметров амфиболитовой фации умеренных или слегка повышенных давлений (680 ${ }^{\circ} \mathrm{C}$ и 7.2 кбар), при невысокой интенсивности переработки пород пояса. Последующие наиболее значимые преобразования связаны с метасоматозом. Его возраст оценивается в $2687 \pm 11 \mathrm{Ma}$ (Slabunov, Singh, 2018). Верхней возрастной границей этих процессов является дайка дацитов, с возрастом 2557 33 млн. лет (Slabunov, Singh, 2018). Метасоматиты, интерпретируемые как пропилиты, могут иметь большое металлогеническое значение. Пренит-пумпеллиитовая фация метамор- 
физма - это поздний этап преобразований и, наиболее вероятно, что он протекал параллельно со становлением гидротермальных кварцевых жил.

Работа выполнена при финансовой поддержке РФФИ (грант 17-55-45005 ИНД-а), является вкладом в выполнение государственного задания КарНЦ РАН (ИГ КарНЦ РАН, проект А18-118020290085-4).

\section{Литература}

1. Метасоматизм и метасоматические породы. Колл. авторов. Ред. В.А. Жариков, В.Л. Русинов. М. Изд-во: Научный мир. 1998. 492с.

2. Метаморфизм и тектоника. Под ред. Е.В. Склярова. М.: Интермет Инжиниринг. 2001. 216 с.

3. Русинов В.А. Геологические и физико-химические закономерности пропилитизации. М.Изд-во: Наука. 1972.

4. Berman R.G. Thermobarometry using multiequilibrium calculations: a new technique with petrological application // Can. Mineral. 1991. V. 29. N 4. P. 833-855.

5. Blundy J.D., Holland T.J.B. Calcic amphibole equilibria and a new amphibole-plagioclase geothermometer. Contrib. Mineral. and Petrol. 1990. V. 104. N. 2. P. 208-224.

6. Grew E.S., Locock A.J., Mills S.J., Galuskina I.O., Galuskin E.V., Hålenius U. Nomenclature of the garnet supergroup // Amer. Mineral. 2013. V. 98. P. 78-811.

7. Kaur P., Zeh A., Chaudhri N., Eliyas N. Unravelling the record of Archaean crustal evolution of the Bundelkhand Craton, northern India using U-Pb zircon-monazite ages, Lu-Hf isotope systematics, and whole-rock geochemistry of granitoids // Precambrian Research. 2016. V. 281. P. 384-413.

8. Nomenclature of amphiboles. Report of the subcommittee on amphiboles of the international mineralogical association commission on new minerals and mineral names // Eur.J. Mineral. 1997. V. 9. P 623-651.

9. Pati J.K., Patel S.C., Pruseth K.L., Malviya V.P., Arima M., Raju S., Pati P., Prakash K. Geology and geochemistry of giant quartz veins from the Bundelkhand Craton, Central India and their implications // Journal of Earth System Science. 2007. V. 116. P. 497-510.

10. Powell R. Regression diagnostics and robust regression in geothermometer/geobarometer calibration: the garnetclinopyroxene geothermometer revised // J. Metamorphic Geol. 1985. V. 3. N. 3. P. 231-243.

11. Pradhan V.R., Meert J.G., Pandit M.K., Kamenov G. and Mondal M.E.A., Paleomagnetic and geochronological studies of the mafic dyke swarms of Bundelkhand craton, central India: Implications for the tectonic evolution and paleogeographic reconstructions // Precambrian Research. 2012. V. 198-199. P. 51-76.

12. Ramakrishnan M., Vaidyanadhan R. Geology of India. Geological Society of India. 2010. 556 p.

13. Saha L., Pant N. C., Pati J. K., Upadhyay D., Berndt J., Bhattacharya A., Satynarayanan M.. Neoarchean high-pressure margarite-phengitic muscovite-chlorite corona mantled corundum in quartz-free high-Mg, $\mathrm{Al}$ phlogopite-chlorite schists from the Bundelkhand craton, north central India // Contrib Mineral Petrol. 2011. V. 161. P. 511-530.

14. Schmidt M.W. Amphibole composition as a function of buffer assemblage and pressure: an experimental approach // EOS, Transactions, American Geophysical Union. AGU. Fall Meeting, 1991. V.72, N.44, Supplement. P. 547.

15. Singh V.K., Slabunov A. The central Bundelkhand Archean greenstone complex, Bundelkhand craton, central India: geology, composition, and geochronology of supracrustal rocks // International Geology Review. 2015. V. 57. P. $1349-1364$.

16. Singh P.K., Verma S.K., Moreno J.A., Singh V.K., Malviya P.K., Oliveira E.P., Mishra S., Arima M., Geochemistry and Sm-Nd isotope systematics of metabasalts from the Babina and Mauranipur greenstone belts, Bundelkhand craton: Implications for tectonic setting and Paleoarchean mantle evolution // Lithos. 2019 b. V. 330-331. P. 90-107. DOI: 10.1016/j.lithos.2019.02.010.

17. Singh V.K., Slabunov A. Two types of Archean supracrustal belts in the Bundelkhand craton, India: Geology, geochemistry, age and implication for craton crustal evolution // Journal of the Geological Society of India. 2016. V. 88. P. 339-348.

18. Slabunov A.I., Singh V.K. Meso-Neoarchaean crustal evolution of the Bundelkhand Craton, Indian Shield: new data from greenstone belts // International Geology Review. 2018. doi.org/10.1080/00206814.2018.1512906.

19. Slabunov A., Singh V.K. The new tectonic division of the Bundelkhand Craton Indian Shield // Труды Ферсмановской научной сессии ГИ КНЦ РАН. 2019

20. SlabunovA., Singh V.K.,KumarB.,XiaoliL.Paleoarcheanzircons fromquartzite of South BundelkhandSupracrustal Complex: origin and implications for crustal evolution in Bundelkhand Craton, Central India // Current Science. 2017. V. 112. P. 794-801. 